\title{
(2) OPEN ACCESS \\ Systemic generalised lymphangiomatosis: unknown aetiology and a challenge to treat
}

\author{
Tess Van Meerhaeghe, ${ }^{1}$ Frederik Vandenbroucke, ${ }^{2}$ Brigitte Velkeniers ${ }^{3}$
}

${ }^{1}$ Nephrology, CUB Erasme, Brussels, Belgium

${ }^{2}$ Radiology, UZ Brussel, Brussels, Belgium

${ }^{3}$ Internal Medicine, UZ Brussel, Brussels, Belgium

Correspondence to

Professor Brigitte Velkeniers; brigitte.velkeniers@uzbrussel.be

Accepted 26 December 2020

Check for updates

(c) BMJ Publishing Group Limited 2021. Re-use permitted under CC BY-NC. No commercial re-use. See rights and permissions. Published by BMJ.

To cite: Van Meerhaeghe T, Vandenbroucke $F_{\text {, }}$

Velkeniers B. BMJ Case

Rep 2021;14:e237331.

doi:10.1136/bcr-2020-

237331

\section{SUMMARY}

We describe a case of a woman diagnosed at the age of 35 years with a generalised mediastinal and abdominal lymphangiomatosis associated with a protein losing enteropathy, who successfully improved when treatment with sirolimus was initiated.

\section{BACKGROUND}

Systemic generalised lymphangiomatosis is a very rare condition commonly appearing during childhood, characterised by proliferation of normal mature lymphatic ducts with formation of numerous cysts in varied body organs. These cysts can occur in any organ except for the brain that lacks lymphatics. ${ }^{1}$ Its aetiology remains unknown, but lymphangiomas are considered to be uncommon benign tumours. Different putative mechanisms of lymphangioma development are proposed including failure of the lymphatic system to connect with or separate from the venous system or abnormal budding of the lymphatic system from the cardinal vein. In adults, sequestration of lymphatic tissue secondary to inflammatory processes or surgical therapy has been incriminated. ${ }^{2}{ }^{3}$ Recent studies suggest the potential role of specific lymphangiogenic growth factors. Increased interleukin-6, vascular endothelial growth factor $c$ (VEGF-c), vascular endothelial growth factor receptor 3 (VEGFR-3) and Prospero Homeobox 1 (prox-1) have been correlated with the genesis of lymphangiomas. ${ }^{4}$ These new insights create new opportunities for treatment, including the use of inhibitors of angiogenesis.

Although lymphangiomas are benign lesions, they may cause significant mortality because of their large sizes, critical locations and the possibility of secondary infections. The lymphangiomatosis spectrum is very heterogeneous in its presentation, and can include microcystic and macrocystic isolated lymphatic malformations, thoracic and intra-abdominal diffuse lymphangiomatosis, and osseous and soft-tissue presentations known as Gorham-Stout disease. ${ }^{1}$

Lung involvement is paramount and the leading cause of death. ${ }^{5}$ Abdominal lymphangiomatosis is rare in adult patients. The most frequent symptoms are abdominal pain. Some patients with limited lymphangiomas are asymptomatic. Few case reports describe adult patients with lymphangiomatosis, gastrointestinal bleeding and hypoproteinaemia, that may be lifethreatening. Intestinal lymphangiectasia is one of the reasons of protein-losing enteropathy. ${ }^{6-9}$

Since the condition is rare there is no uniform treatment strategy for symptomatic patients and evidence-based therapies are lacking. Surgery has been attempted for localised and generalised gastrointestinal disease, but recurrence rates are high. ${ }^{10}$ Various other treatment modalities have been proposed, including radiotherapy, chemotherapy, interferon-alfa and systemic corticosteroids with varied success in small cohorts. ${ }^{11-14}$ A limited number of case reports suggests a potential benefit of angiogenesis inhibitors, such as VEGF inhibitors, mammalion target of rapamycin (mTOR) inhibitors and tyrosine kinase inhibitors. ${ }^{13-17}$

These treatments were successful at a young age of diagnosis but their efficacy in adults remains to be established.

Recent published case reports and a small patient cohort show an adult phenotype resembling lymphangiomatosis, but who are associated with phosphatidylinositol 3 kinase catalytic alpha polypeptide (PIK3CA) gene mutations. These PIK3CA-related overgrowth syndromes (PROS) can lead to asymmetric growth of lymphatics and mimic a systemic lymphangiomatosis. When confronted with patients suffering from PROS, efficacy has been established with sirolimus, and recent evidence shows promising results with BYL719, an inhibitor of PIK3CA. ${ }^{18}$

The present case illustrates the beneficial effect of sirolimus in a therapy resistant generalised lymphangiomatosis in an adult patient and highlights the importance of CT volumetry in the monitoring of the condition. Therefore, sirolimus therapy should be considered for diffuse lymphangiomatosis as it may be effective in improving the condition as illustrated in this patient, with persistent benefit 4 years after the initiation of treatment.

\section{CASE PRESENTATION}

A 35-year-old woman progressively developed abdominal pain, associated with severe lymphoedema of the legs, ascites and diarrhoea. She was not taking any medication and her medical history was unremarkable, except for a sphincterectomy and papillotomy for gallstones, a laparoscopic cholecystectomy and a left ovarectomy after ovarian torsion. She did not have any familial antecedents of similar findings.

She did not smoke and there was no alcohol consumption.

Laboratory results showed a potassium level of $2.4 \mathrm{mmol} / \mathrm{L}$, a calcium level $1.45 \mathrm{mmol} / \mathrm{L}$, an albumin concentration $14 \mathrm{~g} / \mathrm{L}$, uric acid $1.8 \mathrm{mg} / \mathrm{dL}$, gammaglobuline $1.7 \mathrm{~g} / \mathrm{L}$, transferrin saturation $28 \%$, ferritine level $7 \mu \mathrm{g} / \mathrm{L}$, haemoglobin $95 \mathrm{~g} / \mathrm{L}$, mean corpuscular volume (MCV) $72 \mathrm{fL}$, platelets $63 \times 10^{9} / \mathrm{L}$, white cell count of $1.600 \times 10^{9} / \mathrm{L}$, absolute lymphocytes $2.151 \times 10^{9} / \mathrm{L}$ and vitamin $\mathrm{B}_{12} 0.18 \mu \mathrm{g} / \mathrm{L}$. 


\section{INVESTIGATIONS}

An initial CT of the thoracoabdominal region showed a multilobar cystic mass in the mediastinum extending in the retroperitoneum and intraperitoneum. A total body MRI confirmed multiple hyperintense cystic lesions in mediastinum and retroperitoneum on T2-weighted images suggestive of lymphangiomatosis. A biopsy of the cystic lesions was performed under CT guidance, but biopsy was non-diagnostic, because there was not enough tissue sample.

\section{DIFFERENTIAL DIAGNOSIS}

The differential diagnosis should include metastatic ovarian cystic adenocarcinoma, cystic teratoma, lymphangioleiomyomatosis (LAM), PROS syndrome and benign lymphangiomatosis. The diagnosis of metastatic ovarian cystic adenocarcinoma was excluded with normal CA 125 and the atypical aspect on CT scan and MRI. Cystic teratoma usually presents as a complex cystic mass with a considerable solid component and calcifications, moreover the patient had normal alfa fetoprotein and beta-human chorionic gonadotropin (HCG) levels. ${ }^{19}$

PROS syndrome is a genetic disorder that results from somatic, mosaic gain-of-function mutations of the PIK3CA. Most patients present with major deformities and vascular masses that were not seen in the present case. LAM results from progressive proliferation of atypical smooth-muscle like cells. It often occurs as an inherited disorder called tuberous sclerosis complex (TSC), but it can be isolated and sporadic and primarily affects the lungs. Serum VEGF-D may be a useful biomarker in LAM. ${ }^{20}$

We proceeded with an upper gastrointestinal endoscopy that revealed multiple white spots in the duodenum and jejunum. Histopathology of the biopsy showed lymphangiectasia with no evidence of malignancy, nor the presence of LAM cells. Immunostaining for HMB45 was negative, but positive for CD31 and smooth muscle actin. TSC gene analysis was negative, and serum VEGF-D level was normal. Recently PIK3CA gene was analysed in a small skin vascular lesion and the mutation could not be identified.

The diagnosis was generalised lymphangiomatosis with a malabsorption due to protein losing enteropathy.

\section{TREATMENT}

The patient was put on a low-fat protein diet, with weekly infusion of albumin and immunoglobulin supplementation. Pan abdominal radiotherapy, with a total of $14.3 \mathrm{~Gy}$ in 11 fractions, was proposed but was stopped prematurely due to severe gastrointestinal side effects.

In the following years, different treatments, based on recent insights of the pathogenesis of this disease, were administered: sandostatine, low fat with medium chain triglyceride diet, followed by doxycline, beta-blockade and finally thalidomide. All treatments failed to induce significant changes in clinical, biological and radiographic findings. A treatment based on sirolimus $0.8 \mathrm{mg} / \mathrm{m}^{2} / 12$ hours was initiated in January 2016. The dose of sirolimus was adjusted to keep trough concentrations between 6 and $30 \mu \mathrm{g} / \mathrm{L}$.

\section{OUTCOME AND FOLLOW-UP}

Subsequent CT imaging showed a significant regression of the cystic lesions with an estimated volume reduction of $1226 \mathrm{cc}$ to $447 \mathrm{cc}(-64 \%)$ since the introduction of Sirolimus (figure 1A-D). The cystic structures seen on the CT scans were manually segmented by the 'volume tracing function' (Intellispace Portal, Philips, The Netherlands), which implements a region growing

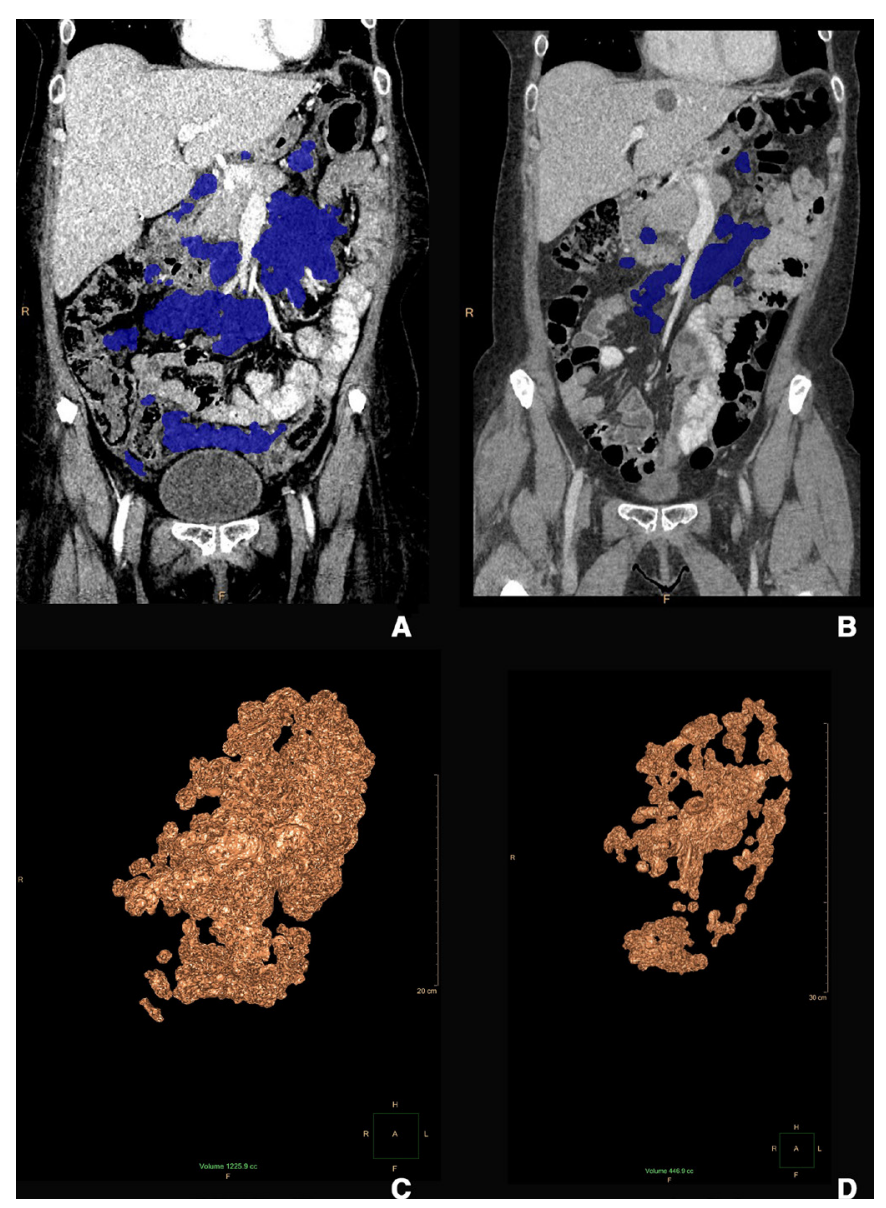

Figure 1 Coronal view of the contrast enhanced CT scans with the selected content of the peritoneal and retroperitoneal cysts, marked in blue. $A, B$ illustrates the lymphangiomatosis at the start $(A)$ and 24 months after start of sirolimus therapy (B). (C,D): Three-D image of the calculated volumes of the selected content as shown in $(A, B)$. This was done for both scans with an interval of 24 months. (C) Before start of therapy-(D) 24 months after start of sirolimus therapy).

algorithm that takes into account the density similarity of the cysts. Those densities were added to the segmentation. When all the cystic structures were selected, the algorithm calculated the content of the volume of interest. ${ }^{2122}$

The patient continued infusion of albumin and immunoglobulin supplementation at a lower frequency with controlled serum albumin, and improvement of initial severe lymphopenia (white cell count of $3.400 \times 10^{9} / \mathrm{L}$, absolute lymphocytes $0.550 \times 10^{9} / \mathrm{L}$ ). The patient lost weight with regression of lymphoedema of lower limbs. She did not experience severe infections since treatment was started. This was indeed a major concern in the presence of severe lymphopenia and immunosuppression with sirolimus.

We postulate that regression of cystic lesions contributed to decreased lymphocyte sequestration and leakage resulting from diminished intestinal lymphangiectasias. Throughout the follow-up, the sirolimus levels were within therapeutic range.

\section{DISCUSSION}

Systemic generalised lymphangiomatosis is a rare disorder and usually becomes symptomatic at a young age. Although the condition is benign in nature, it may lead to severe symptoms and in some cases may have a debilitating course with high 
mortality. Indeed, abdominal lymphangiomatosis can result in severe protein losing enteropathy and gastrointestinal bleeding due to the presence of diffuse intestinal lymphatic abnormalities, as described in the present case report. ${ }^{6-9}$

The lymphopenia as observed in the present case is, however, exceptional and rarely reported.

Whether lymphangiomas are true malformations or neoplastic in nature remains unsettled. Taking into account the unusual proliferation of lymphatics, mTOR inhibitors may represent a promising treatment strategy in the management of the observed lymphatic anomalies, although the level of evidence of efficacy is low and is essentially based on occasional case reports. ${ }^{13-17}$ Patients treated with angiogenesis inhibitors were diagnosed at a young age. One can indeed presume that early intervention may be more promising by intervening in the process of lymphangiomatosis at an early stage. The efficacy at adult age of diagnosis remains uncertain.

In the broad differential diagnosis of lymphangiomatosis, patients should be screened for PIK3CA mutations, because several case reports and a recent published patient cohort have shown adult patients with a phenotype mimicking systemic lymphangiomatosis. ${ }^{18}$

However, we could not detect this mutation in the patient.

The present observation adds support to the possible beneficial treatment of sirolimus in adult patients with diffuse lymphangiomatosis. Our patient was treated with sirolimus with dose adjustment according to measured trough levels with a favourable evolution of the associated protein losing enteropathy. This could not be achieved with previous therapeutic regimens, administered in parallel with supportive treatment. The treatment was not only efficient in controlling disease symptoms but also induced radiological regression of the cystic lesions. Volumetric CT as illustrated in the present case report constitutes a good measure to evaluate efficacy of treatment. ${ }^{21}{ }^{22} \mathrm{~A}$ similar observation has recently been made in the treatment of an adult patient with diffuse pulmonary lymphangiomatosis treated with sirolimus with a decrease in mediastinal masses and an improvement in pulmonary function. ${ }^{23}$

Therefore, this case report highlights an important role of the angiogenesis inhibitors in the treatment of symptomatic and therapy resistant systemic generalised lymphangiomatosis.

Lymphopenia is not a limiting factor. Increase in absolute numbers of lymphocytes under sirolimus treatment might even be considered as a positive result with a possible benefit, including a decreased risk of secondary infectious complications.

Further insights in the pathogenesis of the disease and targeted treatments can result in a better outcome of patients with diffuse lymphangiomatosis.

Learning points

- Systemic generalised lymphangiomatosis is a benign disorder that may mimic malignancy with severe symptoms and aggressive behaviour.

- There is no uniform consensus on treatment of generalised lymphangiomatosis.

- Promising results can be expected with angiogenesis inhibitors.
Contributors The three authors have been treating the patient and did ensure follow-up. TVM has written the case report. FV and BV contributed to the redaction.

Funding The authors have not declared a specific grant for this research from any funding agency in the public, commercial or not-for-profit sectors.

Competing interests None declared.

\section{Patient consent for publication Obtained.}

Provenance and peer review Not commissioned; externally peer reviewed.

Open access This is an open access article distributed in accordance with the Creative Commons Attribution Non Commercial (CC BY-NC 4.0) license, which permits others to distribute, remix, adapt, build upon this work non-commercially, and license their derivative works on different terms, provided the original work is properly cited and the use is non-commercial. See: http://creativecommons.org/ licenses/by-nc/4.0/.

\section{REFERENCES}

1 Blei F. Lymphangiomatosis: clinical overview. Lymphat Res Biol 2011;9:185-90.

2 Rockson SG. Laboratory models for the investigation of lymphangiomatosis. Microvasc Res 2014;96:64-7.

3 Wiegand S, Eivazi B, Barth PJ, et al. Pathogenesis of lymphangiomas. Virchows Arch 2008;453:1-8.

4 Ji R-C, Eshita Y, Xing L, et al. Multiple expressions of lymphatic markers and morphological evolution of newly formed lymphatics in lymphangioma and lymph node lymphangiogenesis. Microvasc Res 2010;80:195-201.

5 Kadakia KC, Patel SM, Yi ES, et al. Diffuse pulmonary lymphangiomatosis. Can Respir J 2013;20:52-4

6 Pang L, Kong J. Case report: an extremely rare case report: small intestine diffuse lymphangiomatotis with jejunum focal cavernous hemangioma in a 51 year-old female suffering from melena. Int J Clin Exp Med 2017;10:15551-4.

7 Atalay E, Erdogdu HI, Tur BK. Intestinal lymphangiomatosis presenting with proteinlosing enteropathy. Akademik Gastroenteroloji Dergisi 2017;16:36-9.

8 Lepre L, Costa G, Baldini D, et al. Emergency presentation of cystic lymphangioma of the colon: a case report and literature review. Int J Surg Case Rep 2016;24:162-5.

9 Lin R-Y, Zou H, Chen T-Z, et al. Abdominal lymphangiomatosis in a 38-year-old female: case report and literature review. World J Gastroenterol 2014;20:8320-4.

10 Ilhan M, Oner G, Alibeyoglu A, et al. Primary intestinal lymphangiomatosis of the ileum in an adult-the role of surgical approach. J Surg Case Rep 2016;2016:rjw133-4.

11 Ozeki M, Kanda K, Kawamoto N, et al. Propranolol as an alternative treatment option for pediatric lymphatic malformation. Tohoku J Exp Med 2013;229:61-6.

12 Ozeki M, Fukao T, Kondo N. Propranolol for intractable diffuse lymphangiomatosis. $N$ Engl J Med 2011;364:1380-2.

13 Reinglas J, Ramphal R, Bromwich M. The successful management of diffuse lymphangiomatosis using sirolimus: a case report. Laryngoscope 2011;121:1851-4

14 Triana P, Dore M, Cerezo VN, et al. Sirolimus in the treatment of vascular anomalies. Eur J Pediatr Surg 2017;27:86-90.

15 Adams DM, Trenor CC, Hammill AM, et al. Efficacy and safety of sirolimus in the treatment of complicated vascular anomalies. Pediatrics 2016;137:e20153257.

16 Laforgia N, Schettini F, De Mattia D, et al. Lymphatic malformation in newborns as the first sign of diffuse lymphangiomatosis: successful treatment with sirolimus. Neonatology 2016;109:52-5.

17 Amodeo I, Cavallaro G, Raffaeli G, et al. Abdominal cystic lymphangioma in a term newborn: a case report and update of new treatments. Medicine 2017:96:e5984.

18 Venot Q, Blanc T, Rabia SH, et al. Targeted therapy in patients with PIK3CA-related overgrowth syndrome. Nature 2018:558:540-6.

19 DI Marco M, Grassi E, Vecchiarelli S, et al. Retroperitoneal lymphangioma: a report of 2 cases and a review of the literature regarding the differential diagnoses of retroperitoneal cystic masses. Oncol Lett 2016;11:3161-6.

20 Young L, Lee H-S, Inoue Y, et al. Serum VEGF-D a concentration as a biomarker of lymphangioleiomyomatosis severity and treatment response: a prospective analysis of the multicenter international lymphangioleiomyomatosis efficacy of sirolimus (Miles) trial. Lancet Respir Med 2013;1:445-52.

21 Planz VB, Lubner MG, Pickhardt PJ. Volumetric analysis at abdominal CT: oncologic and non-oncologic applications. Br J Radio/ 2019:92:20180631.

22 Suzuki K. Computerized Segmentation of Organs by Means of Geodesic ActiveContour Level-Set Algorithm. In: El-Baz A, Acharya UR, Mirmehdi M, et al, eds. Multi modality state-of-the-art medical image segmentation and registration methodologies. Boston: Springer, 2011: 103-28.

23 Gurskytè V, Zeleckienè I, Maskoliūnaitè V, et al. Successful treatment of diffuse pulmonary lymphangiomatosis with sirolimus. Respir Med Case Rep 2020;29:101014 
Copyright 2021 BMJ Publishing Group. All rights reserved. For permission to reuse any of this content visit https://www.bmj.com/company/products-services/rights-and-licensing/permissions/

BMJ Case Report Fellows may re-use this article for personal use and teaching without any further permission.

Become a Fellow of BMJ Case Reports today and you can:

- Submit as many cases as you like

- Enjoy fast sympathetic peer review and rapid publication of accepted articles

- Access all the published articles

Re-use any of the published material for personal use and teaching without further permission

Customer Service

If you have any further queries about your subscription, please contact our customer services team on +44 (0) 2071111105 or via email at support@bmj.com.

Visit casereports.bmj.com for more articles like this and to become a Fellow 